\title{
Track and Circulation Analysis of Tropical and Extratropical Cyclones that Cause Strong Precipitation and Streamflow Events in the New York City Watershed
}

\author{
KATHERINE L. TOWEY \\ Program in Earth and Environmental Sciences, The Graduate Center, City University of New York, New York, New York \\ JAMES F. BOOTH \\ Department of Earth and Atmospheric Sciences, City College of the City University of New York, and Program in Earth \\ and Environmental Sciences, The Graduate Center, City University of New York, New York, New York \\ ALLAN FREI \\ Department of Geography, Hunter College, and Program in Earth and Environmental Sciences, The Graduate Center, \\ and CUNY Institute for Sustainable Cities, City University of New York, New York, New York \\ MARK R. SINCLAIR \\ Department of Applied Aviation Sciences, Embry-Riddle Aeronautical University, Prescott, Arizona
}

(Manuscript received 18 October 2017, in final form 10 April 2018)

\begin{abstract}
The top 100 basin-scale 1-day precipitation, multiday precipitation, and 1-day streamflow events from 1950 to 2012 are examined for the Ashokan reservoir, a key water source for New York City. Through a cyclone association algorithm, extratropical cyclones (ETCs) are found to be associated with the majority of the top 100 precipitation and streamflow events. Tropical cyclones (TCs) generate the second-most top 100 one-day and multiday precipitation events, with more than two-thirds of these TCs having undergone extratropical transition. Furthermore, TCs that pass over the region are approximately 7 and 4 times more likely to generate a top 100 one-day precipitation and one-day streamflow event, respectively, than ETCs. Lagrangian cyclone track analysis shows cool season ETCs take a more meridional path compared to warm season ETCs. A composite analysis shows that for the top 100 one-day precipitation events, ETCs have relatively less moisture but stronger upper-level support than TCs. Due in part to TCs, heavy precipitation events occur more often in the warm season, whereas high streamflow events occur mainly in the cool season. Despite this difference, approximately $43 \%$ of the top 100 events, which represent many of the very strongest events, overlap for all three metrics. While high temperature and specific humidity anomalies accompany all top 100 events, the magnitude of the anomalies is greatest for isolated streamflow events. This analysis provides a reference to forecasters and water managers regarding the relative and synoptic-scale behavior of different storm types for isolated and concurrent precipitation and streamflow events.
\end{abstract}

\section{Introduction}

Heavy precipitation events can impact water resource management by affecting the quantity and quality of water used for municipal, agricultural, and industrial purposes. The extent to which a precipitation event negatively impacts a water supply system is dependent on preexisting streamflow levels and surface conditions,

\footnotetext{
Corresponding author: K. L. Towey, ktowey@gradcenter.cuny.
} edu such as soil moisture and permeability, as well as the duration and intensity of rainfall associated with the circulation and spatial size of a storm. In the midlatitudes, a wide range of atmospheric phenomena that include extratropical cyclones (ETCs), tropical cyclones (TCs), and mesoscale convective systems can result in precipitation. The types of atmospheric phenomena associated with ordinary and extreme precipitation events have been examined through global (e.g., Pfahl and Wernli 2012; Catto and Pfahl 2013; Utsumi et al. 2017), hemispheric (e.g., Hawcroft et al. 2012), and regional 
(e.g., Schumacher and Johnson 2006; Barlow 2011; Kunkel et al. 2012; Agel et al. 2015) analyses. These studies demonstrate that the association of atmospheric phenomena to precipitation events is sensitive to the spatial scale of the study area. Therefore, for this study we categorize the relationship between different atmospheric phenomena and the strongest basin-scale precipitation and streamflow events.

In the midlatitudes, extreme precipitation events identified in the European Center for MediumRange Weather Forecasts (ECMWF) interim reanalysis (ERA-Interim) coincided with an ETC $80 \%$ of the time (Pfahl and Wernli 2012). The contribution of ETCs to extreme precipitation events is less for the U.S. Northeast compared to the midlatitudes as a whole because TCs have a more significant role. Although ETCs and their associated fronts account for a majority of extreme precipitation events in the Northeast (e.g., Kunkel et al. 2012; Agel et al. 2015), a small yet significant portion of extreme precipitation events are attributed to TCs (e.g., Konrad 2001; Barlow 2011; Kunkel et al. 2012; Agel et al. 2015; Marquardt Collow et al. 2016). The contribution of TCs and ETCs to extreme precipitation events varies among studies because of differences among the definition of extremes, time periods studied, precipitation data sources, and methods of storm-type association. Regardless, storm-type association with the heaviest precipitation events allows us to identify characteristic synoptic-scale features (e.g., Milrad et al. 2009; Milrad et al. 2014; Moore et al. 2015; Agel et al. 2018). This information can be valuable in mediumrange forecasts to water resource managers, who can enact necessary preparation measures for their water supply system.

While previous studies have examined the contribution of various storm types on different spatial scales, little work has been done at the basin scale. Our study area focuses on the Ashokan reservoir located in the Catskill Mountains in southeastern New York State because of its role in supplying approximately $40 \%$ of the drinking water for New York City (NYCDEP 2018). In southeastern New York, the nature of the seasonal cycle of extreme precipitation and streamflow events is complex. While extreme precipitation events occur year-round, the intensity of such events is found to be equally high regardless of season (Agel et al. 2015), although the most intense events occur most frequently between August and October (Matonse and Frei 2013). The seasonal cycle of extreme streamflow events is bimodal, with the largest events occurring during March and April as well as between August and October (Matonse and Frei 2013). In watersheds, flooding can occur because of heavy precipitation that results in high streamflow levels (e.g., Nakamura et al. 2013; Teale et al. 2017), though this occurs more frequently during the warm season (Matonse and Frei 2013). In the cool season, high streamflow events are largely dependent on snowpack (e.g., Matonse and Frei 2013; Dumanski et al. 2015; Newton and Burrell 2016). In the Catskills, snowmelt processes are critical drivers of cool season streamflow (Pradhanang et al. 2011) and rain-on-snow events have a significant role in winter runoff events (Pradhanang et al. 2013). It is due to the distinct seasonality as well as the variety of physical mechanisms associated with generating precipitation and streamflow that heavy precipitation does not always result in high streamflow (Frei et al. 2015). Across 390 U.S. watersheds, very heavy precipitation resulted in very high discharge days only $36 \%$ of the time, yet studies rarely affirm the notion that "heavy precipitation does not necessarily lead to high stream discharge" (Ivancic and Shaw 2015). This motivates a central question of this study in which we seek to examine how the time evolution of synoptic-scale features differs for the strongest precipitation and streamflow events that occur concurrently and in isolation of one another.

Our analysis is designed to better understand the storm types and synoptic-scale circulation features associated with the strongest precipitation and streamflow events at the basin scale. The work herein accomplishes this objective by analyzing the seasonality and time evolution of synoptic-scale features based on storm type as well as on sets of isolated and concurrent precipitation and streamflow events. Part of the motivation for documenting these details has to do with the issue of how climate change may impact the frequency and causes of such precipitation and streamflow events. Thus, there is a need to characterize and understand how strong precipitation and streamflow events relate to large-scale atmospheric circulation patterns in the present climate.

The present study is also motivated by previous work that focused on associating cyclone tracks with extreme wind and storm surge events (Booth et al. 2015, 2016). We will utilize Lagrangian tracks of ETCs to determine if a dominant track pathway emerges for the storms associated with the strongest precipitation and streamflow events. The track of a cyclone provides forecasters with a zeroth-order approximation in determining where impacts from a storm are likely to occur. The accurate prediction of cyclone tracks is dependent on medium-range weather models, which resolve the physics at the synoptic scale and rely on parameterizations for precipitation. We then expect the models to have more skill in predicting the location of a cyclone center compared to the location of heavy precipitation. 
The results presented here help clarify the evolution of large-scale atmospheric circulation patterns associated with the strongest precipitation and streamflow events, which will be useful additional information to both forecasters and water resource managers.

The remainder of this paper is organized as follows. Data and methods are described in section 2. Section 3 describes the storm-type contribution and synopticscale circulation features associated with the strongest precipitation and streamflow events. Section 4 examines the seasonality and overlap between the top 100 precipitation and streamflow events. The paper concludes with a summary of the results in section 5 .

\section{Data and methods}

\section{a. Study area}

The Ashokan reservoir (Fig. 1), whose area covers nearly $500 \mathrm{~km}^{2}$, is one of two reservoirs in New York City's Catskill water supply system. Water from the other reservoir in New York City's Catskill water supply system, the Schoharie, flows into the Ashokan reservoir (NYCDEP 2018). Reservoirs located within the Catskills consist largely of protected lands that remain mostly forest and farmland (Seager et al. 2012) and are largely unchanged during the period of this study.

\section{b. Data}

This study utilizes daily precipitation data from five precipitation gauges in and around the Ashokan reservoir and streamflow data from one stream gauge located within the Ashokan reservoir (Table 1). Precipitation data are obtained from the Northeast Regional Climate Center at Cornell University (www.nrcc.cornell.edu). Streamflow data are obtained from the United States Geological Survey surface water website (https:// waterdata.usgs.gov/nwis/sw). It is important to note that because we utilize gauges, a potential bias is introduced into our analysis. This bias occurs as a result of wind-induced precipitation undercatch, which can occur during all seasons, but is most common during large frozen precipitation events in winter (e.g., Groisman and Legates 1994; Rasmussen et al. 2012). During very heavy precipitation events, precipitation gauge undercatch has been found to not significantly impact rainfall amounts (e.g., Sevruk 1982; Folland 1988).

For this study, we rank daily precipitation and streamflow amounts from highest to lowest and focus our analysis on the top 100 events for three hydrometeorological metrics: 1-day precipitation, multiday precipitation, and 1-day streamflow. Multiday precipitation events range in duration from 2 to 5 days of continuous

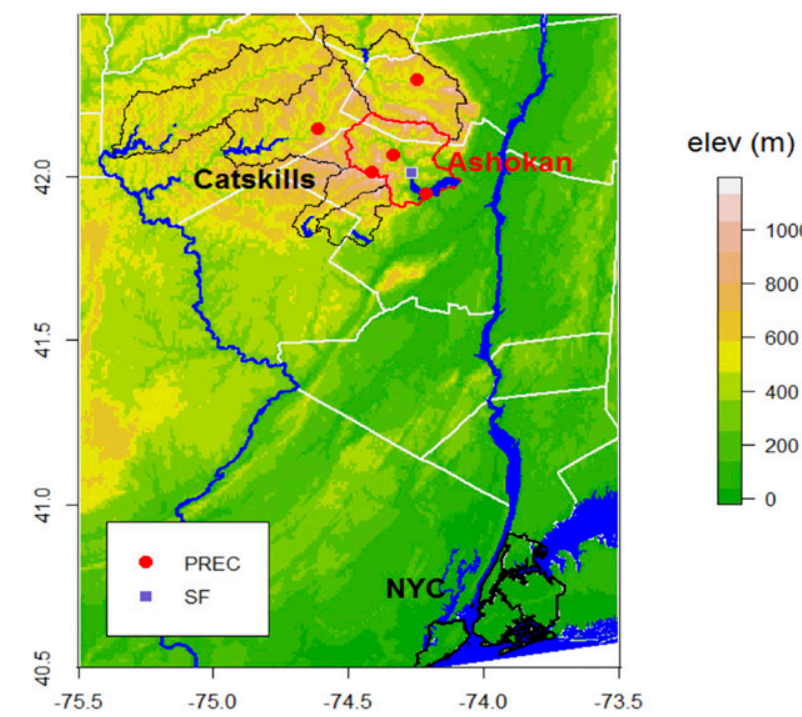

FIG. 1. Latitude-longitude gridded topographical map of study area including the Ashokan watershed (red contour), the Catskills region (thin black contour), and New York City (thick black contour) as well as the precipitation (red circles) and streamflow (purple square) stations used in this study.

rainfall. Precipitation and streamflow events during all months of the year from 1950 to 2012 are considered in this analysis. This time period is chosen based on the availability of an objective characterization of extratropical transition events that is described below. We choose to outright pick the top 100 events regardless of season in order to do a direct comparison of precipitation and streamflow events associated with TCs and ETCs. Of all basin-scale precipitation and streamflow events observed at Ashokan between 1950 and 2012, the top $2.33 \%, 4.55 \%$, and $0.90 \%$ represent the top 100 oneday precipitation, multiday precipitation, and one-day streamflow events, respectively. The number of standard deviations that the 100th event is away from the mean for each metric is 2.89 for 1-day precipitation, 2.01 for multiday precipitation, and 4.09 for 1-day streamflow events.

To provide the reader with an idea of the magnitudes and rates of occurrence of the top 100 events, return periods are calculated using the threshold excess approach to extreme value analysis described by Coles (2001), in which a generalized Pareto probability distribution function is fit to a subset of events at the tail of the distribution, defined by an event magnitude greater than a specified threshold. This theoretical distribution allows one to estimate the probability of occurrence for events of different magnitudes, which are then typically expressed as return periods. Results presented here are derived using the guidance and software provided by 
TABLE 1. Precipitation and streamflow gauge stations in the Ashokan reservoir.

\begin{tabular}{lclccc}
\hline \hline & Station ID number & \multicolumn{1}{c}{ Station name } & Elevation $(\mathrm{m})$ & Latitude $\left({ }^{\circ} \mathrm{N}\right)$ & Longitude $\left({ }^{\circ} \mathrm{W}\right)$ \\
\hline Precipitation & 300254 & Arkville & 412.1 & 42.15000 & 74.61667 \\
& 306570 & Phonecia & 323.1 & 42.06722 & 74.33556 \\
& 307721 & Shokan Brown Station & 159.1 & 41.95000 & 74.21667 \\
& 307799 & Slide Mountain & 808.0 & 42.01667 & 74.41660 \\
Streamflow & 309516 & Windham & 463.3 & 42.30000 & 74.25000 \\
& 1362500 & Esopus Creek at Coldbrook & 189.4 & 42.01417 & 74.27056 \\
\hline
\end{tabular}

Gilleland and Katz (2016), which is implemented in the $\mathrm{R}$ statistical programming language ( $\mathrm{R}$ Core Team 2014). Parameter values are estimated using the L-moments method, which provides parameter estimates that are robust in regard to the choice of threshold value. Figure 2 shows the empirical hydrometeorological data along with the extreme value analysis results. Heavy 1-day precipitation events have occurred throughout our period of record (Fig. 2a). The 10-yr return period value (i.e., probability of occurrence is $0.1 \mathrm{yr}^{-1}$ ) for (a)

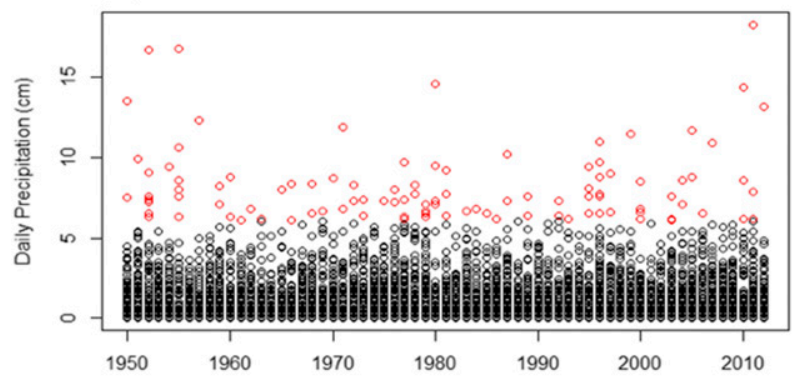

(c)

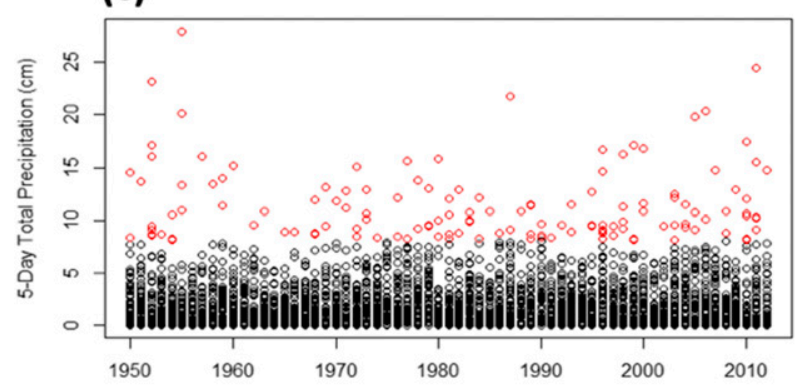

(e)

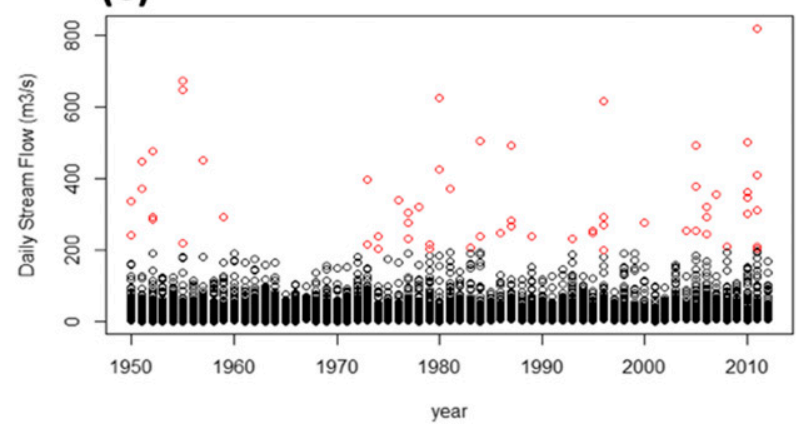

(b)

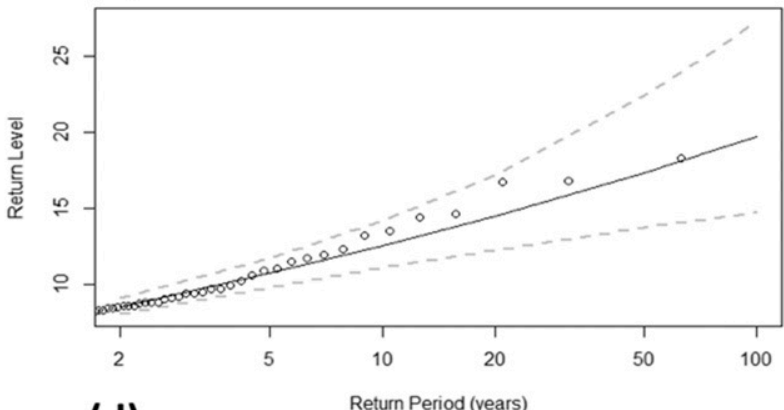

(d)

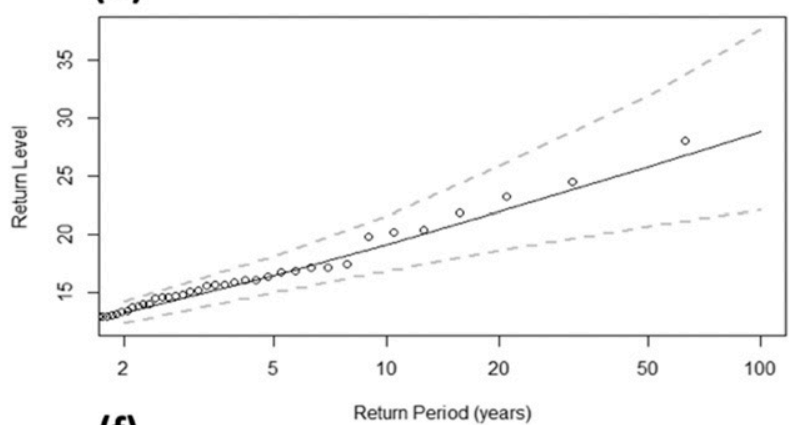

(f)

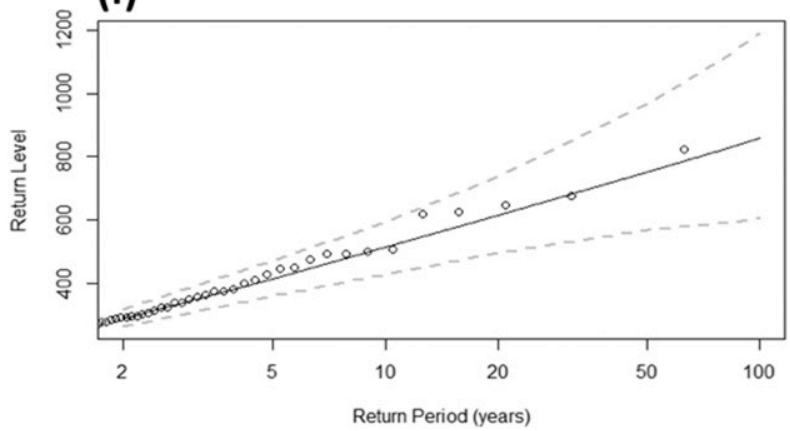

FIG. 2. (left) Annual empirical observations of all events (black circles) and top 100 events (red circles) and (right) return periods for top 100 events for (a),(b) 1-day precipitation; (c),(d) multiday presentation; and (e),(f) 1-day streamflow. In return period plots, the solid line is the best fit while dashed lines indicate the 95 th percentile confidence intervals. 
1-day precipitation events is $\sim 12 \mathrm{~cm}$, and the $100-\mathrm{yr}$ return period value (i.e., probability of occurrence is $0.01 \mathrm{yr}^{-1}$ ) is $\sim 20 \mathrm{~cm}$ (Fig. 2b). For multiday precipitation events (Figs. 2c,d), 10- and 100-yr return period values are 18 and $27 \mathrm{~cm}$, respectively. Large 1-day streamflow events are scattered less evenly through the period of record, with the most conspicuously infrequent period during the 1960s (Fig. 2e). Ten- and 100-yr return period values for 1-day streamflow events are $\sim 500$ and $\sim 800 \mathrm{~m}^{3} \mathrm{~s}^{-1}$, respectively (Fig. 2f). Historically, events with average daily streamflow levels greater than $\sim 400 \mathrm{~m}^{3} \mathrm{~s}^{-1}$, which corresponds to a 5 -yr return period in the Esopus Creek, often require treatment for turbidity (R. Mukundan, New York City Department of Environmental Prediction, 2018, personal communication).

In addition to the precipitation and streamflow data, we utilize reanalysis data to examine the large-scale circulation patterns associated with the strongest precipitation and streamflow events. To cover the period of interest, we use the ECMWF Twentieth Century Reanalysis (ERA-20C; Hersbach et al. 2015) from 1950 to 1978 and the ERA-Interim (Dee et al. 2011) from 1979 to 2012 , both of which are at $1.5^{\circ}$ horizontal resolution.

\section{c. Overlap of hydrometeorological events}

We analyze the number of hydrometeorological metrics that concurrently result from the same event. A 1-day buffer is placed around the 1-day precipitation and 1-day streamflow events to account for the possibility that a storm passage included 0000 UTC, which would cause the observations to have a date that is shifted by 1 day. These dates are compared with each date in the multiday precipitation event, which can range from 2 to 5 days. Following the comparison, we determine seven possible sets of events: three sets of one-category events, three sets of two-category events, and one set of threecategory events. The one-category sets include events that occurred in isolation (i.e., 1-day precipitation that did not result in multiday precipitation or 1-day streamflow). Two- and three-category sets include events that concurrently occurred in two or three of the metrics, respectively.

\section{d. Storm-type association}

The hydrometeorological events are associated with cyclone tracks related to TCs and ETCs. For TCs, we use the National Hurricane Center's Atlantic hurricane database (HURDAT2; Landsea and Franklin 2013). The database provides 6-hourly observations regarding the date, location, classification, and intensity of the TC. We also document which TCs undergo extratropical transition, which is determined by an objective algorithm that measures the low-level $(600-850 \mathrm{hPa})$ thermal asymmetry and upper-level $(300-600 \mathrm{hPa})$ geostrophic wind speed difference (Sinclair 2002). Extratropical transition occurs if the maximum thermal asymmetry for the entire TC track exceeds $25 \mathrm{~m}$ and the upper-level cold core attains a value less than $-10 \mathrm{~m} \mathrm{~s}^{-1}$. The location of extratropical transition is where the thermal asymmetry first exceeds $15 \mathrm{~m}$, provided the upperlevel geostrophic wind difference is less than $-2 \mathrm{~ms}^{-1}$ (M. Sinclair 2017, personal communication). These determinations of extratropical transition are based on the cyclone phase space concepts of Hart (2003) as implemented by Evans and Hart (2003).

When referring to TCs, we include those TCs that underwent extratropical transition and those that did not. Separate from the TC association is the designation of dual TC and ETC (TC-ETC). This designation is assigned when there is an event associated with both a TC and ETC track over the duration of the event. These events could be associated with predecessor rain events (e.g., Galarneau et al. 2010) or ETCs following the passage of a TC.

ETC tracks are identified by a Lagrangian tracking algorithm, the Modeling, Analysis, and Prediction (MAP) Climatology of Midlatitude Storm Area (MCMS; Bauer et al. 2016), which is applied to ERA-20C from 1950 to 1978 and to ERA-Interim from 1979 to 2012. The MCMS tracking algorithm follows low pressure centers by using 6-hourly sea level pressure reanalysis to identify the latitude and longitude of the cyclone center. Cyclones are retained if they are trackable for at least $48 \mathrm{~h}$. Since both TCs and ETCs are identified by the MCMS tracking algorithm, we remove duplicates of TCs that appear in the MCMS database.

To be associated with a top 100 event, the cyclone center must pass within $1000 \mathrm{~km}$ of Ashokan $\left(42^{\circ} \mathrm{N}\right.$, $74.25^{\circ} \mathrm{W}$ ). If multiple cyclone centers are found within $1000 \mathrm{~km}$ of Ashokan on the day of an event, we determine the cyclone closest to Ashokan to be the cyclone of greatest contribution to the event. If no cyclone center is found within $1000 \mathrm{~km}$ on the day of an event, the event is classified as "other." The designation of "other" indicates that either the cyclone was not traveling fast enough for the tracker to resolve the cyclone center or that the event was caused by another phenomenon, such as a stationary front.

When comparing the top 100 events among the three hydrometeorological metrics, the storm-type association may differ depending on the metric. For example, a 1-day event could have the association of "other" if no ETC occurred on the day prior to, the day of, or the day following the event; however, one day during a multiday precipitation event that excludes the 1-day event could 
TABLE 2. Count of top 100 events for each hydrometeorological metric associated with storm types: ETCs; TCs, which include TCs that do and do not undergo extratropical transition (ET); "other"; and TC-ETC. Each metric has a total of 100 events and thus the count can be equated to a percentage.

\begin{tabular}{llccr}
\hline \hline & & 1-day precipitation & Multiday precipitation & 1-day streamflow \\
\hline ETCs & & 74 & 71 & 80 \\
TCs & Non-ET & 6 & 3 & 2 \\
& ET & 14 & 12 & 6 \\
Other & & 6 & 7 & 10 \\
TC-ETC & & 0 & 7 & 2 \\
\hline
\end{tabular}

be associated with an ETC. To avoid overcomplication, we retain the storm-type association from each metric, in which case some sets of concurrent events may have multiple storm-type associations, such as "other" and ETC. In such cases, the calculation of percentages related to each storm type counts each storm type as half toward the concurrent event.

\section{e. Composites}

ERA-20C and ERA-Interim are utilized to create composites for mean sea level pressure, 2-m temperature, 925-hPa specific humidity, 500-hPa geopotential heights, and 200-hPa wind speeds. A 63-yr daily climatology based on 1950-2012 is created for each variable. The climatology is smoothed with a 5-day running mean, and the subsequent result is used for calculating the anomaly field of each variable. We utilize the full fields for mean sea level pressure and 500-hPa geopotential heights despite averaging all times of the year. While the magnitude of mean sea level pressure and 500-hPa geopotential heights vary seasonally, the composite fields are spatially similar regardless of season for each storm type, such that low pressure or low geopotential heights would be indicative of a cyclone accompanied by an upper-level trough. For all anomaly composites, statistical significance is calculated using a Monte Carlo method in which we generate a set of 1000 composites based on randomly sampled anomaly fields. The number of randomly sampled fields for the Monte Carlo simulations always matches the number of precipitation or streamflow events in question. Seasonal bins, which are based on the seasonality of the storm types or metrics that are being composited, constrain the randomly sampled fields for the Monte Carlo simulations. Randomly sampled fields for ETC composites, for example, are sampled from all seasons because ETCs occur yearround, compared to TC composites, which are constrained to the warm season (JJA and SON).

\section{Storm-type contribution and synoptic-scale circulation of top 100 events}

The extent to which ETCs and TCs are attributed to the top 100 precipitation and streamflow events at Ashokan is summarized in Table 2. Based on our storm-type association, ETCs and TCs account for $74 \%$ and $20 \%$ of the top 100 one-day precipitation events, respectively. A similar grouping of storm types is found for the top 100 multiday precipitation events. The relative contribution of TCs for both precipitation metrics increases if we focus on fewer events (e.g., top 10 events), indicating that TCs have resulted in some of the heaviest precipitation events at Ashokan (Figs. 3a,b).
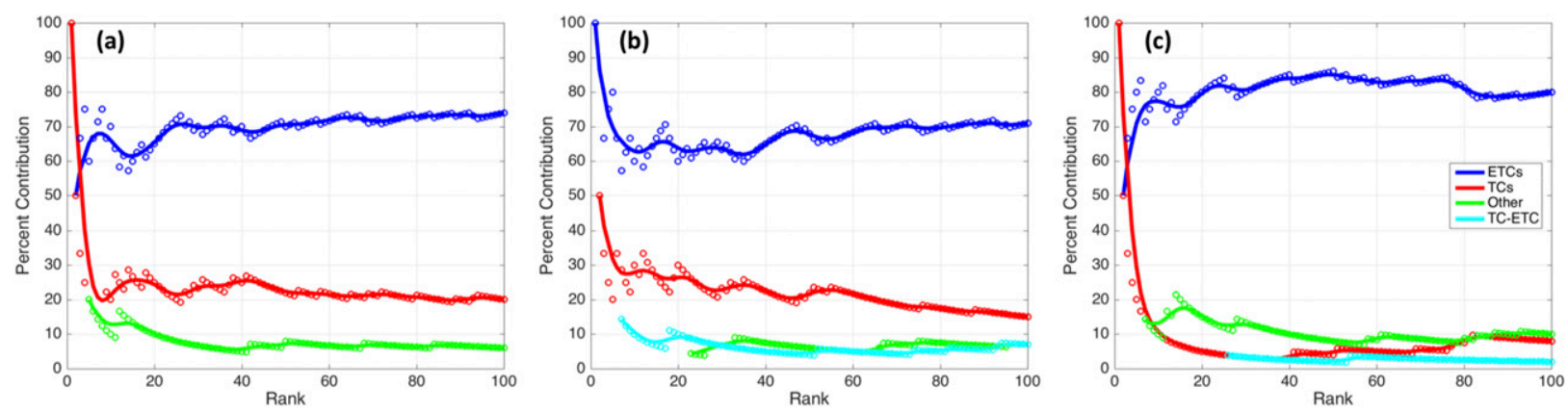

FIG. 3. Relative percent contribution based on the rank of the storm-type association for (a) 1-day precipitation, (b) multiday precipitation, and (c) 1-day streamflow events. Storm-type association includes ETCs (blue), TCs (red), "other" (green), and TC-ETC (light blue), as defined in the text. The line fits are generated using a locally weighted linear regression method (loess, span $=0.49)$. 
The storm-type contribution for the top 100 one-day streamflow events shows that $80 \%$ of the events are associated with ETCs, while TCs account for only $8 \%$. Aside from Hurricane Irene (2011), which resulted in the largest one-day precipitation event and one-day streamflow event at Ashokan, there are no TCs associated with the top 25 one-day streamflow events (Fig. 3c). The storm-type classification "other" is attributed to 10 of the top 100 one-day streamflow events, which is the largest contribution from "other" of any of the hydrometeorological metrics.

For TCs, we also examine the frequency of TCs that underwent extratropical transition. Of all TC-associated events, $70 \%$ of 1 -day precipitation, $80 \%$ of multiday precipitation, and $75 \%$ of 1 -day streamflow events underwent extratropical transition. A similar ratio exists for all TC events in the region, regardless of whether they resulted in a heavy precipitation or high streamflow event (not shown). In some cases, two different storm types were associated with the same event; seven multiday precipitation events and two 1-day streamflow events were associated with both an ETC and TC track and are counted separately from the individual ETC and TC counts. We refer to these events as a dual ETC and TC storm type. This storm type association could include TCs that undergo extratropical transition, but they also include a distinct ETC.

ETCs are the dominant storm type for all hydrometeorological events in the Ashokan reservoir. However, it is useful to consider the probability that an ETC or TC could generate a top 100 one-day precipitation or oneday streamflow event. Between 1950 and 2012, there were 2164 ETCs and 77 TCs whose tracks passed within $500 \mathrm{~km}$ of Ashokan (not shown). Assuming each cyclone produced a nonnegligible amount of precipitation in the region, the top 100 one-day precipitation and one-day streamflow events coincided with ETCs $3.14 \%$ and $2.82 \%$ of the time, respectively. TCs, however, coincided with the top 100 one-day precipitation and oneday streamflow events $22.08 \%$ and $7.79 \%$ of the time, respectively. A similar ratio exists for TCs that underwent extratropical transition in the region. Of the 77 TCs whose tracks passed within $500 \mathrm{~km}$ of Ashokan, 55 underwent extratropical transition. These TCs that
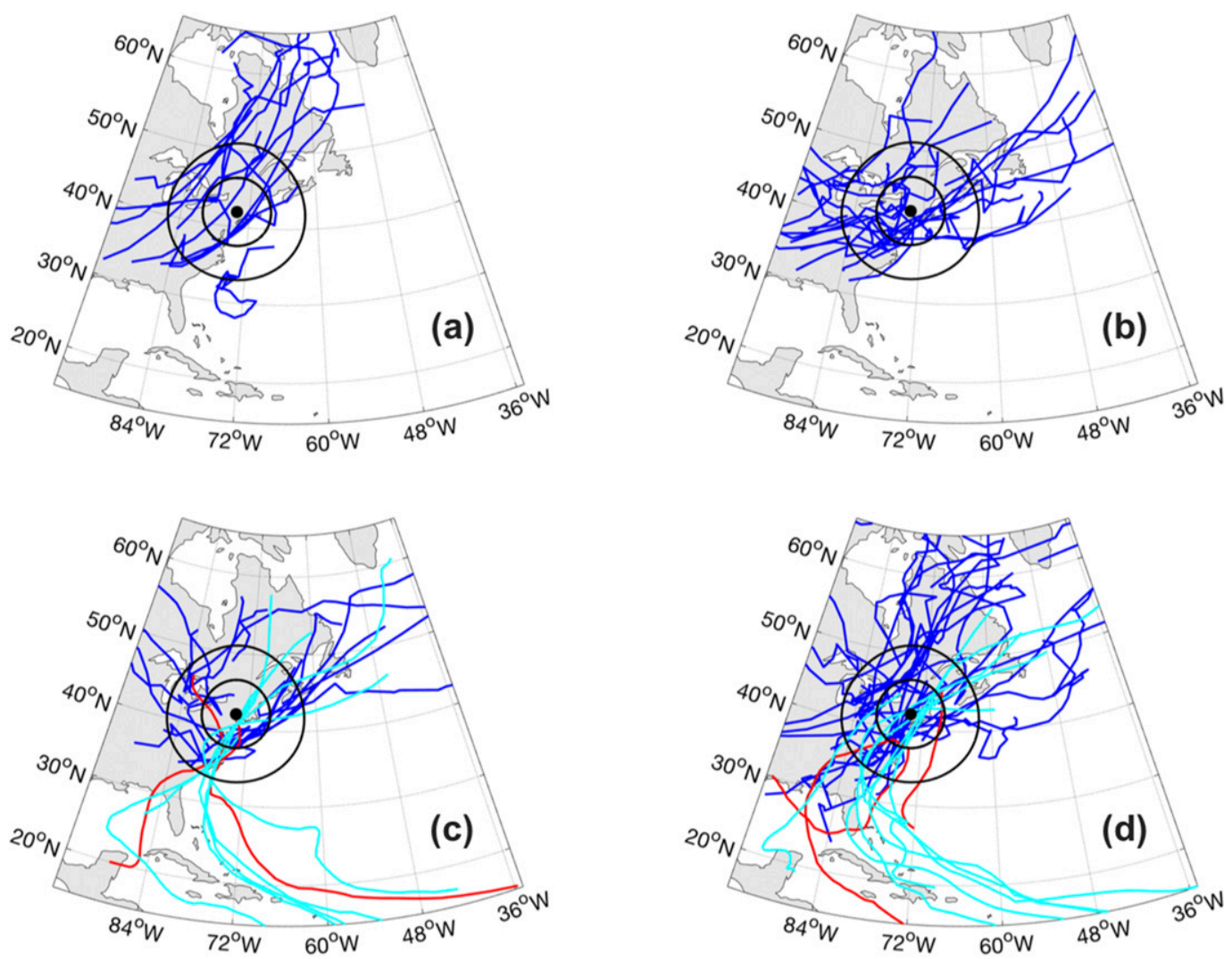

FIG. 4. ETC (blue), TCs that do not undergo extratropical transition (red), and TCs that do undergo extratropical transition (cyan) tracks for the top 100 one-day precipitation events that occurred during (a) DJF, (b) MAM, (c) JJA, and (d) SON. The black dot represents the location of Ashokan. Inner and outer circles represent a radius of 500 and $1000 \mathrm{~km}$ from Ashokan, respectively. 


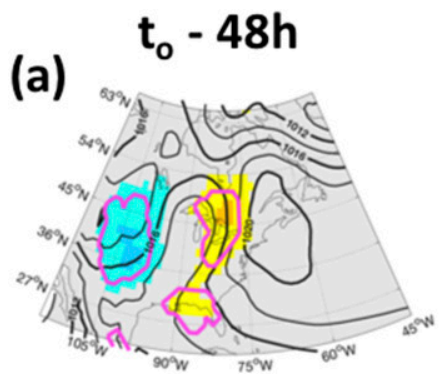

(c)

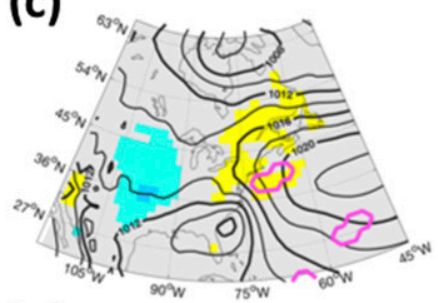

(e)

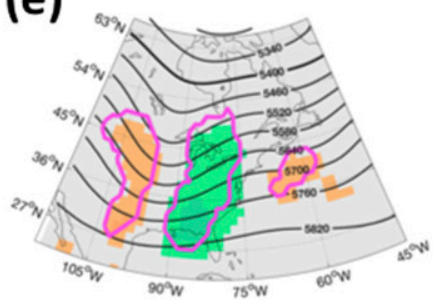

(g)

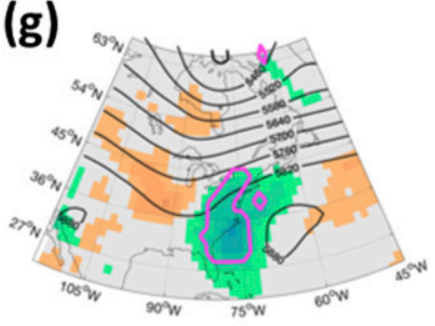

(i)

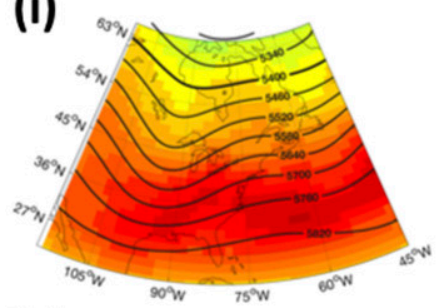

(k)

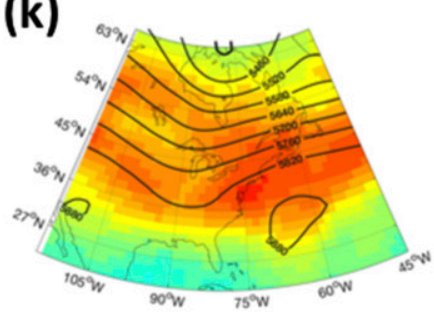

(b) $t_{0}$

(b)

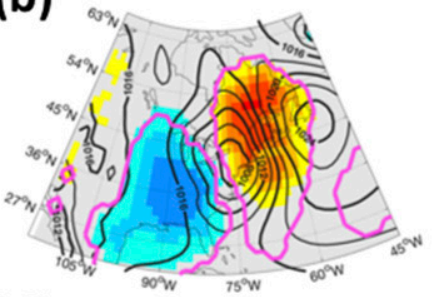

(d)

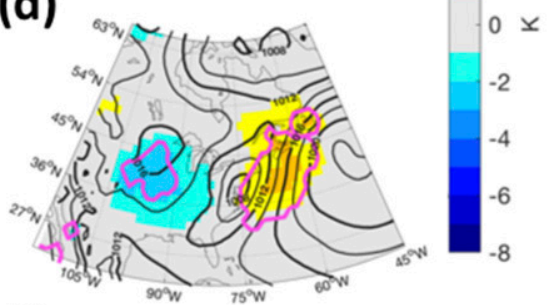

(f)

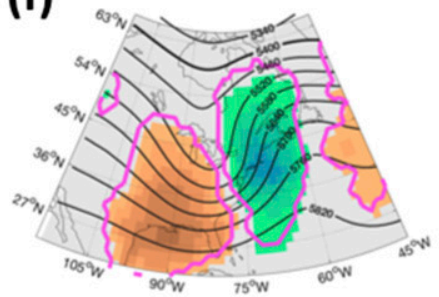

(h)

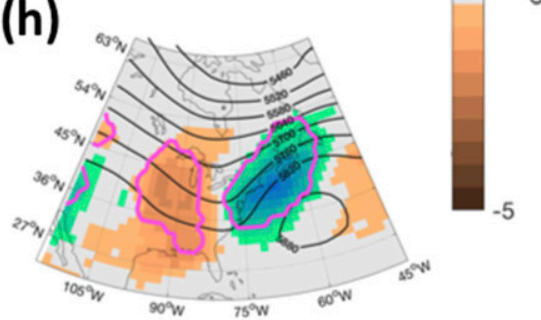

(j)

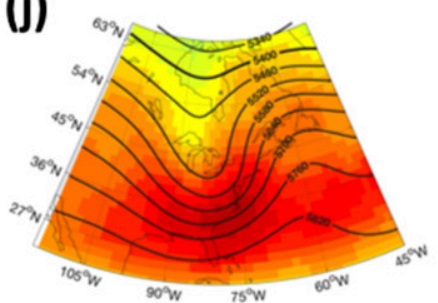

(I)

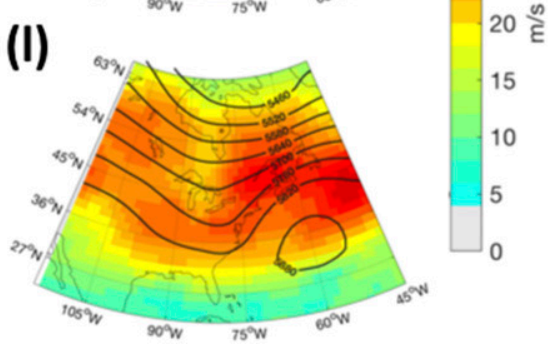

FIG. 5. Composites for ETCs in the first, third, and fifth rows and TCs in the second, fourth, and sixth rows associated with top 100 one-day precipitation events for (left) $48 \mathrm{~h}$ prior to the events and (right) the day of the events for (a)-(d) 2-m temperature anomalies (K; shading) and averaged mean sea level pressure ( $\mathrm{hPa}$; black contours), 
underwent extratropical transition coincided with the top 100 one-day precipitation and one-day streamflow events $21.82 \%$ and $9.09 \%$ of the time, respectively. It is important to note here that if the same ETC or TC is associated with multiple events, the cyclone is only counted once in these calculations. While these probabilities do not take into consideration atmospheric moisture availability or soil moisture content, they do illustrate the influence of tropical moisture in the midlatitude environment.

To examine the synoptic-scale circulation features associated with ETCs and TCs, we utilize the ETCs and TCs associated with the top 100 one-day precipitation events since many of these events are also found in the top 100 multiday precipitation and one-day streamflow events. Additionally, the top 100 one-day precipitation events are associated with the highest counts of TCs and ETCs among the three metrics.

Separating the ETC tracks seasonally shows 12 events in DJF, 18 events in MAM, 16 events in JJA, and 28 events in SON. Most ETC tracks during DJF exhibit a strong meridional component in their pathway (Fig. 4a), whereas ETC tracks during JJA reveal a more pronounced zonal component in their pathway (Fig. 4c). There is also a difference in the meridional and zonal components of the ETC tracks that occur during MAM and SON. The ETC tracks during SON have a larger meridional component than zonal component (Fig. 4d) compared to the ETC tracks during MAM (Fig. 4b). During both MAM and SON, however, many of the ETC tracks move near or along the coastline, which suggests that the ocean could provide additional moisture to an ETC. Many of the TC tracks (Figs. 4c,d), which move parallel to the East Coast of the United States, overlap with the track density maximum of all TCs that travel within $500 \mathrm{~km}$ of the region (not shown). For both ETCs and TCs, the spread among the top 100 tracks is nearly as large as the spread among all cyclones that travel within $500 \mathrm{~km}$ of Ashokan (not shown).

To test if there are distinct synoptic-scale characteristics shared by the storms that cause the top 100 oneday precipitation events, we analyze the synoptic-scale circulation features through composites based on storm type. For ETCs, a broad area of low pressure develops over the Mississippi River Valley (Fig. 5a) downstream of a positively tilted trough over the central United
States (Fig. 5e), $48 \mathrm{~h}$ prior to the 1-day precipitation event. Analogous to cluster C2 from Agel et al. (2018), the upper-level trough becomes negatively tilted over the eastern United States by the day of the 1-day precipitation event (Fig. 5f) with the closed low pressure system located over the Northeast (Fig. 5b), which coincides with the left exit region of an intensifying jet streak (Fig. 5j), indicative of a strong baroclinic system. The position of the composite cyclone near the composite anticyclone over the North Atlantic creates a strong pressure gradient that leads to southeasterly flow that could transport anomalously warm and moist air toward the Northeast (Figs. 5b,f). The time evolution of 925-hPa specific humidity anomalies suggests that the moisture advection could be transporting air from the subtropics (Figs. 5e,f). The exact source of the moisture, however, cannot be discerned from this analysis (e.g., Dacre et al. 2015).

Composites associated with all TCs, regardless of whether the TCs underwent extratropical transition, show the composite cyclone center is located near the southeastern U.S. coastline (Fig. 5c) and removed from the upper-level flow (Fig. $5 \mathrm{~g}$ ), $48 \mathrm{~h}$ prior to the 1-day precipitation event. As the composite TC propagates up the East Coast, the upper-level trough extends down toward the southeastern United States, strengthening vertical shear near the storm (Fig. 5k). Since a majority of the TCs undergo extratropical transition, the increased shear is likely a signature of the transition process (e.g., Evans et al. 2017). On the day of the 1-day precipitation event, the composite cyclone has moved farther north along the coastline toward the midAtlantic (Fig. 5d), with the upper-level trough seemingly encompassing the TC into the midlatitude flow, which subsequently intensifies the downstream jet streak (Fig. 5l). Southerly to southeasterly flow around the composite cyclone transports anomalous moisture, most likely sourced from the eastern Caribbean, on the day prior to (not shown) and the day of the 1-day precipitation event into the Northeast (Fig. 5h).

\section{Seasonality and overlap of top 100 events}

An examination of the seasonality of the top 100 hydrometeorological events at Ashokan shows that the heaviest 1-day precipitation and multiday precipitation

(e)-(h) 925-hPa specific humidity anomalies ( $\mathrm{g} \mathrm{kg}^{-1}$; shading) and mean 500-hPa geopotential height ( $\mathrm{m}$; black contours), and (i)-(l) mean 200-hPa wind speeds ( $\mathrm{m} \mathrm{s}^{-1}$; shading) and mean $500-\mathrm{hPa}$ geopotential height ( $\mathrm{m}$; black contours). Anomaly fields of statistical significance at the 99th percentile are contoured in magenta. 

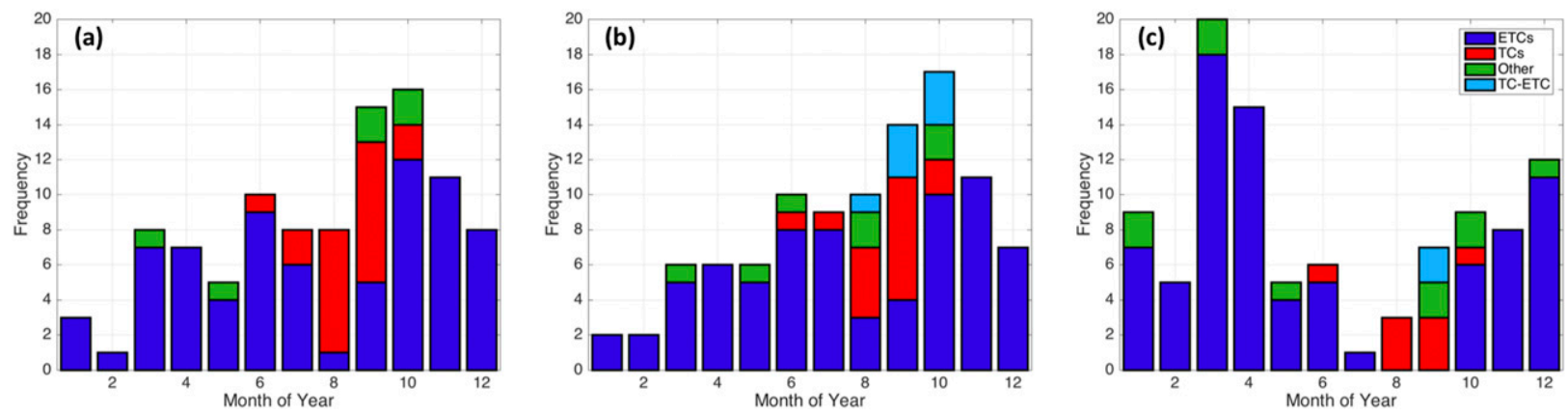

FIG. 6. Monthly count of top 100 events based on storm-type association for (a) 1-day precipitation, (b) multiday precipitation, and

(c) 1-day streamflow events. Storm-type association includes ETCs (blue), TCs (red), "other"' (green), and TC-ETC (light blue).

events occur most frequently from June through November (Figs. 6a,b). During these months, which coincide with the North Atlantic hurricane season, TCs, including those that undergo extratropical transition, account for almost $30 \%$ of 1 -day precipitation and $21 \%$ of multiday precipitation events. If we consider TCs that undergo extratropical transition as a distinct category, $21 \%$ of 1 -day precipitation and $17 \%$ of multiday precipitation events during the warm season are attributed to TCs that underwent extratropical transition.

The number of top 100 one-day precipitation and multiday precipitation events is greatest during SON, when approximately $40 \%$ of the top 100 events occur at Ashokan. Even if TCs are removed, most events still occur in SON. However, removing TCs would lead to a bimodal distribution with a secondary peak in June and a minimum in August. The fewest top 100 one-day precipitation and multiday precipitation events occur in DJF; however, 1-day precipitation and multiday precipitation events associated with ETCs do occur during all seasons. In contrast, 1-day streamflow events largely occur from December through April (Fig. 6c), with half of the top 100 one-day streamflow events occurring in MAM, during which the occurrence of rain-on-snow processes is most frequent (e.g., Matonse and Frei 2013; Dumanski et al. 2015; Newton and Burrell 2016). "Other" events are associated with all hydrometeorological events and occur at any time of the year.

The frequency with which the strongest hydrometeorological events occur in isolation (i.e., one-category events) or concurrently as two- or three-category events is determined by separating the events into seven sets: three one-category sets, three two-category sets, and one three-category set (Table 3 ). Three-category events account for the highest contribution among the top 100 events, with $44 \%$ of 1 -day precipitation, $36 \%$ of multiday precipitation, and $50 \%$ of 1 -day streamflow events resulting in a concurrent event. This means that there were 36 distinct three-category events in which eight 1-day precipitation events and fourteen 1-day streamflow events included two or more 1-day events that occurred within the same multiday event, which can range from 2 to 5 days in duration (for clarification, see Table 6). These three-category events often rank the highest among the top 100 events of each hydrometeorological metric. Two-category events involving high streamflow rarely occur since high streamflow events occur most frequently from December through April, whereas

TABLE 3. Count and median rank of isolated (one-category) and concurrent (two- and three-category) precipitation and streamflow events.

\begin{tabular}{llccc}
\hline \hline & & 1-day precipitation & Multiday precipitation & 1-day streamflow \\
\hline One category & Count & 18 & 26 & 33 \\
& Median rank & 75 & 30.5 & 65 \\
Two categories & Count & 32 & 51 & - \\
& Median rank & 40 & - & 7 \\
& Count & 6 & 7 & 60 \\
Median rank & Count & - & 63 & 10 \\
Three categories & Median rank & - & 36 & 59.5 \\
& Count & 44 & 28.5 & 30 \\
& Median rank & 41 & & 33.5 \\
\hline
\end{tabular}



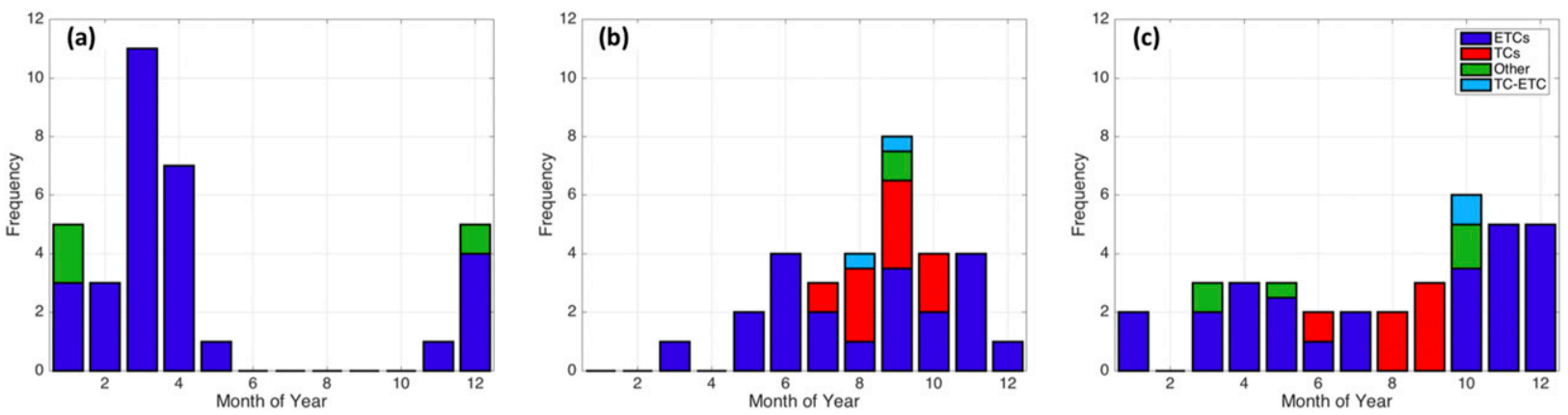

FIG. 7. As in Fig. 6, but for (a) isolated streamflow events, (b) concurrent 1-day precipitation and multiday precipitation events, and (c) three-category events.

heavy precipitation events occur most often from June through November. Over $60 \%$ of the top 100 one-day precipitation and multiday precipitation events between June and November do not result in a top 100 streamflow event. The large number of concurrent precipitation events involving 1-day precipitation and multiday precipitation, as compared to one-category precipitation events, indicates that the strongest multiday precipitation events usually involve at least one day of very heavy precipitation, rather than resulting from prolonged weak rainfall.

Of these seven sets of isolated and concurrent precipitation and streamflow events, we focus on three: isolated one-category streamflow events, two-category 1-day precipitation and multiday precipitation events, and three-category events. Isolated 1-day precipitation and multiday precipitation events are not included because their seasonality and atmospheric conditions are similar to that of the two-category set. Two-category events involving high streamflow are not included because there are so few cases.

Nearly all of the isolated streamflow events occur between December and March (Fig. 7a), with many of these events associated with ETCs (Table 4). Concurrent 1-day precipitation and multiday precipitation events account for approximately one-third of their respective top 100 events (Table 5). These concurrent 1-day precipitation and multiday precipitation events largely occur throughout the warm season, with a maximum in September (Fig. 7b). While the majority of concurrent 1-day precipitation and multiday precipitation events are associated with ETCs, almost one-third of the concurrent 1-day precipitation and multiday precipitation events are associated with TCs. Threecategory events occur year-round, with a slightly larger frequency between October and December (Fig. 7c). ETCs are attributed to most of the three-category events (Table 6). Six of the three-category events are associated with TCs, including Diane (1955), Agnes (1972), David
(1979), Floyd (1999), Ivan (2004), and Irene (2011). Four three-category events are associated with the multiple storm-type designation of ETC and "other," while one three-category event is fully designated as "other."

TABLE 4. Dates of top 100 events associated with isolated streamflow events. Storm-type association includes ETCs, TCs, "other," and TC-ETC, as defined in the text. The appended " $\times n$," where $n$ represents a number, refers to the number of ETC tracks associated with an event. This number does not necessarily indicate that there was that number of distinct storms, as multiple tracks can be associated with the same storm.

\begin{tabular}{lcl}
\hline & One category: 1 -day streamflow & \\
\hline \multicolumn{1}{c}{ Date } & Rank & Storm type \\
\hline 31 Mar 1960 & 89 & ETC \\
4, 5 Apr 1960 & 71,90 & ETC $\times 2$ \\
26 Feb 1961 & 97 & ETC $\times 2$ \\
1 Apr 1962 & 86 & ETC \\
10 Mar 1964 & 98 & ETC $\times 2$ \\
8, 9 Dec 1974 & 46,59 & ETC \\
13, 14 Mar 1977 & 70,50 & ETC \\
6 Mar 1979 & 57 & ETC \\
25 Mar 1979 & 53 & ETC \\
15, 16 Feb 1984 & 65,99 & ETC \\
5, 6 Apr 1984 & 6,48 & ETC \\
30 Mar 1993 & 96 & ETC $\times 2$ \\
11 Apr 1993 & 73 & ETC \\
17 Apr 1993 & 75 & ETC $\times 2$ \\
27 Jan 1996 & 29 & ETC \\
24 Jan 1999 & 88 & ETC \\
14 Jan 2005 & 87 & Other \\
30 Nov 2005 & 39 & ETC \\
18 Jan 2006 & ETC \\
12 May 2006 & 44 & ETC $\times 2$ \\
5 Mar 2008 & 95 & ETC \\
8 Mar 2008 & 53 & ETC $\times 2$ \\
12 Dec 2008 & 93 Jan 2010 & ETC \\
23 Mar 2010 & Other \\
1 Dec 2010 & 7 Mar 2011 & ETC \\
21 Dec 2012 & ETC \\
\hline
\end{tabular}


TABLE 5. As in Table 4, but for concurrent 1-day precipitation and multiday precipitation events. The date in the multiday precipitation column indicates the last day of the event, while the number following the date in parentheses indicates the length of the multiday precipitation event. The appended * indicates a TC that underwent extratropical transition.

\begin{tabular}{|c|c|c|c|c|}
\hline \multicolumn{2}{|c|}{ 1-day precipitation } & \multicolumn{2}{|c|}{ Multiday precipitation } & \multirow[b]{2}{*}{ Storm type } \\
\hline Date & Rank & Date & Rank & \\
\hline 21 Nov 1952 & 23 & 23 Nov 1952 (5) & 9 & ETC \\
\hline 3 Nov 1954 & 21 & 5 Nov 1954 (4) & 64 & ETC \\
\hline 13, 14 Aug 1955 & 41,31 & 15 Aug 1955 (5) & 6 & TC (Connie) \\
\hline 31 Oct 1955 & 92 & 31 Oct 1955 (2) & 53 & ETC \\
\hline 2 Oct 1959 & 37 & 2 Oct 1959 (4) & 51 & TC* (Gracie) \\
\hline 13 Sep 1960 & 27 & 14 Sep $1960(5)$ & 19 & TC* (Donna) \\
\hline 6 Dec 1962 & 67 & 8 Dec 1962 (3) & 81 & $\mathrm{ETC} \times 2$ \\
\hline 9 Aug 1965 & 39 & 10 Aug 1965 (2) & 98 & ETC \\
\hline 3 Nov 1966 & 34 & 4 Nov 1966 (3) & 99 & ETC \\
\hline 30 May 1968 & 83 & 2 Jun 1968 (5) & 43 & ETC $\times 2$ \\
\hline 29 Jul 1969 & 71 & 30 Jul 1969 (4) & 31 & ETC $\times 3$ \\
\hline 23 Oct 1970 & 28 & 24 Oct 1970 (3) & 45 & ETC \\
\hline 28 Aug 1971 & 9 & 29 Aug 1971 (3) & 35 & TC* (Doria) \\
\hline 14 Sep 1971 & 69 & 15 Sep 1971 (4) & 52 & TC (Heidi), TC-ETC \\
\hline 15 May 1978 & 44 & 19 May 1978 (5) & 26 & $\mathrm{ETC} \times 2$ \\
\hline 27 Nov 1979 & 63 & 27 Nov 1979 (3) & 80 & ETC \\
\hline 30 Jun 1980 & 19 & 1 Jul 1980 (3) & 71 & $\mathrm{ETC} \times 2$ \\
\hline 28 Sep 1985 & 80 & 28 Sep $1985(2)$ & 55 & TC* (Gloria) \\
\hline 20 Sep 1989 & 84 & 23 Sep $1989(5)$ & 50 & Other, TC* (Hugo) \\
\hline 1 Jun 1992 & 60 & 2 Jun 1992 (3) & 77 & ETC \\
\hline 6 Oct 1995 & 38 & 8 Oct 1995 (5) & 76 & $\mathrm{TC}^{*}(\mathrm{Opal})$ \\
\hline 14 Jul 1996 & 18 & 16 Jul 1996 (4) & 12 & TC* (Bertha) \\
\hline 18 Sep 1996 & 51 & 19 Sep 1996 (3) & 97 & ETC \\
\hline 12 Sep 1997 & 24 & 12 Sep 1997 (2) & 84 & ETC \\
\hline 6 Jun 2000 & 32 & 7 Jun 2000 (3) & 46 & ETC \\
\hline $15 \mathrm{Jul} 2000$ & 70 & 17 Jul 2000 (4) & 11 & ETC \\
\hline 1 Jun 2003 & 98 & 1 Jun 2003 (5) & 78 & $\mathrm{ETC} \times 2$ \\
\hline 2 Sep 2003 & 50 & 4 Sep 2003 (5) & 39 & Other, ETC \\
\hline 13 Aug 2004 & 65 & 14 Aug 2004 (4) & 74 & TC* (Bonnie), TC-ETC \\
\hline 14 Mar 2010 & 30 & 16 Mar 2010 (4) & 41 & ETC \\
\hline 19 Sep 2012 & 7 & 19 Sep 2012 (2) & 22 & ETC \\
\hline
\end{tabular}

Surface weather maps from the NOAA Central Library's Daily Weather Map Archive (https://library. noaa.gov/Collections/Digital-Documents/US-DailyWeather-Maps) and the NOAA Weather Prediction Center (http://www.wpc.ncep.noaa.gov/archives/web_pages/ sfc/sfc_archive.php) are utilized for events designated as "other" to determine a possible cause for the strong hydrometeorological event, which appears to be a stalled frontal system for all cases.

The evolution of synoptic-scale circulation features is examined through composites in order to highlight important similarities and differences between isolated and concurrent hydrometeorological events (Fig. 8). The general movement of the closed low pressure system in all composites is from the south-central United States toward the greater New York City area. This movement is mirrored in many of the cyclone tracks, which exhibit a greater meridional propagation component than zonal propagation component (not shown).
The movement of the closed low pressure system in the isolated streamflow composites remains inland (Figs. 8a-c). In those composites involving precipitation events, the low pressure system movement is closer to the U.S. East Coast (Figs. 8d-i). Strong anomalous nearsurface warming precedes the isolated streamflow events by 2 days (Fig. 8a). A similar but weaker pattern exists for the three-category events (Fig. 8g). However, for the concurrent 1-day precipitation and multiday precipitation events, the temperature anomaly is near zero (Fig. 8d). A similar pattern exists for the $925-\mathrm{hPa}$ specific-humidity anomalies (not shown), such that the three-category events composite resembles an average of the isolated streamflow events composite and the concurrent 1-day precipitation and multiday precipitation events composite, similar to that shown in Fig. 5f. This suggests that the anomalous warming and moistening of the environment is a necessary condition for high streamflow events. However, the significance of 
TABLE 6. As in Table 4, but for three-category events.

\begin{tabular}{|c|c|c|c|c|c|c|}
\hline \multicolumn{2}{|c|}{ 1-day precipitation } & \multicolumn{2}{|c|}{ Multiday precipitation } & \multicolumn{2}{|c|}{ 1-day streamflow } & \multirow[b]{2}{*}{ Storm type } \\
\hline Date & Rank & Date & Rank & Date & Rank & \\
\hline 26 Nov 1950 & 6 & 26 Nov 1950 (3) & 24 & 25, 26 Nov 1950 & 45,23 & $\mathrm{ETC} \times 2$ \\
\hline 31 Mar 1951 & 16 & 31 Mar 1951 (3) & 27 & 30, 31 Mar 1951 & 12,18 & ETC, Other \\
\hline 6 Apr 1952 & 90 & 6 Apr $1952(2)$ & 87 & 5, 6 Apr 1952 & 33,72 & $\mathrm{ETC} \times 2$ \\
\hline 9, 10 Jul 1952 & 81,3 & $10 \mathrm{Jul} 1952$ (2) & 3 & $10 \mathrm{Jul} 1952$ & 30 & $\mathrm{ETC} \times 2$ \\
\hline 11, 12 Dec 1952 & 46,62 & 13 Dec $1952(3)$ & 15 & 11 Dec 1952 & 10 & ETC \\
\hline 19 Aug 1955 & 14 & 19 Aug 1955 (2) & 30 & 18, 19 Aug 1955 & 81,51 & TC* (Diane) \\
\hline 15,16 Oct 1955 & 48,2 & 18 Oct $1955(5)$ & 1 & $15,16,17$ Oct 1955 & $3,2,84$ & $\mathrm{ETC} \times 2$ \\
\hline 21 Dec 1957 & 8 & 21 Dec 1957 (3) & 14 & 20, 21 Dec 1957 & 79,11 & ETC \\
\hline 25 Oct 1959 & 64 & 25 Oct 1959 (3) & 25 & 24 Oct 1959 & 31 & ETC \\
\hline 22 Jun 1972 & 58 & 26 Jun 1972 (5) & 20 & 23 Jun 1972 & 82 & TC (Agnes) \\
\hline 9 Nov 1972 & 36 & 9 Nov 1972 (2) & 90 & 9 Nov 1972 & 100 & ETC \\
\hline 29, 30 Jun 1973 & 88,86 & 1 Jul 1973 (3) & 34 & 30 Jun 1973 & 52 & ETC \\
\hline 21 Dec 1973 & 54 & 22 Dec $1973(3)$ & 61 & 21 Dec 1973 & 15 & ETC \\
\hline 27 Jan 1976 & 40 & 28 Jan 1976 (3) & 40 & 27 Jan 1976 & 22 & ETC \\
\hline 9 Nov 1977 & 17 & 9 Nov 1977 (5) & 17 & 8, 9 Nov 1977 & 27,35 & ETC \\
\hline 9 Jan 1978 & 35 & 10 Jan 1978 (4) & 89 & 9 Jan 1978 & 24 & $\mathrm{ETC} \times 2$ \\
\hline 6, 7 Sep 1979 & 93,72 & 7 Sep $1979(2)$ & 32 & 6 Sep 1979 & 78 & TC* (David) \\
\hline 22 Mar 1980 & 4 & 23 Mar 1980 (3) & 16 & 21, 22 Mar 1980 & 4,13 & ETC \\
\hline 12 May 1981 & 22 & 13 May 1981 (3) & 42 & 12 May 1981 & 63 & $\mathrm{ETC} \times 2$ \\
\hline 29 May 1984 & 68 & 31 May 1984 (5) & 38 & 30 May 1984 & 74 & Other, ETC \\
\hline 4, 5 Apr 1987 & 59,15 & 5 Apr $1987(5)$ & 4 & 31 Mar; 4, 5 Apr 1987 & $38,8,34$ & $\mathrm{ETC} \times 4$ \\
\hline 29 Nov 1993 & 97 & 29 Nov 1993 (2) & 49 & 28 Nov 1993 & 49 & ETC \\
\hline 22 Oct 1995 & 49 & 22 Oct 1995 (2) & 36 & 21 Oct 1995 & 40 & ETC \\
\hline 12 Nov 1995 & 20 & 12 Nov 1995 (2) & 86 & 12 Nov 1995 & 42 & ETC \\
\hline 20 Oct 1996 & 12 & 22 Oct $1996(4)$ & 23 & 20 Oct 1996 & 80 & Other \\
\hline 2 Dec 1996 & 43 & 2 Dec 1996 (2) & 79 & 2 Dec 1996 & 37 & $\mathrm{ETC} \times 2$ \\
\hline 16 Sep 1999 & 11 & 18 Sep 1999 (4) & 10 & 17 Sep 1999 & 69 & TC* (Floyd) \\
\hline 17 Dec 2000 & 75 & 20 Dec $2000(5)$ & 57 & 17 Dec 2000 & 36 & $\mathrm{ETC} \times 2$ \\
\hline 18 Sep 2004 & 29 & 19 Sep $2004(2)$ & 48 & 18 Sep 2004 & 41 & TC (Ivan) \\
\hline 3 Apr 2005 & 25 & 4 Apr 2005 (3) & 59 & 2, 3 Apr 2005 & 16,9 & ETC \\
\hline 8 Oct 2005 & 10 & 12 Oct $2005(5)$ & 7 & 13 Oct 2005 & 77 & TC*-ETC (TD 22) \\
\hline 26, 27 Jun 2006 & 77,78 & 29 Jun 2006 (5) & 5 & 26, 27, 28 Jun 2006 & $32,92,25$ & ETC \\
\hline 16 Apr 2007 & 13 & 18 Apr 2007 (4) & 21 & 16 Apr 2007 & 20 & ETC \\
\hline 1 Oct 2010 & 5 & 2 Oct $2010(5)$ & 8 & 1 Oct 2010 & 7 & Other, ETC \\
\hline 11 Mar 2011 & 42 & 13 Mar 2011 (4) & 95 & 11 Mar 2011 & 14 & Other, ETC \\
\hline 28, 29 Aug 2011 & 1,94 & 29 Aug 2011 (2) & 2 & 28 Aug 2011 & 1 & TC* (Irene) \\
\hline
\end{tabular}

the anomalous warmth and moisture likely differs for the isolated streamflow and three-category events. Since most of the isolated streamflow events occur in the cool season, the anomalous warmth suggests that the melting of snowpack may cause the high streamflow. The average 2-m temperature associated with the isolated streamflow events is approximately $5^{\circ} \mathrm{C}$, which is warm enough to cause melting, but because of the ClausiusClapeyron relationship, would be too low for a storm to generate heavy precipitation.

Each set of one-, two-, and three-category events would have different potential impacts on the Ashokan reservoir. The question of whether a storm will generate flooding depends on the precipitation amount as well as the existing soil, river, and reservoir conditions. Important preexisting conditions to consider include the size and thermal state of the snowpack during the cool season and the soil moisture level in the warm season. High streamflow events that occur in the absence of heavy precipitation (i.e., isolated 1-day streamflow events) are characterized by significantly warmer-thanaverage temperatures. Since these isolated streamflow events occur most often in the cool season, we speculate that the warm advection in the storm contributes to snowmelt, which is known to contribute to high streamflow events (Pradhanang et al. 2013). Over half of the events that include a high streamflow event coinciding with heavy precipitation (i.e., a three-category event or a two-category event that includes streamflow) occur during the warm season, when reservoirs are typically at their lowest levels (Matonse et al. 2013). This suggests that high streamflow levels could be the result of heavy precipitation during the warm season. Additionally, three-category events include some of the 


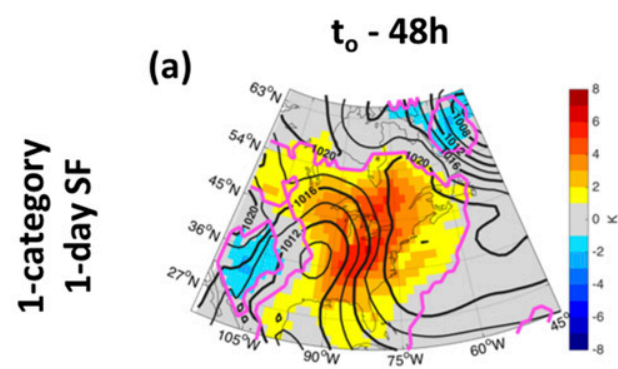

(d)

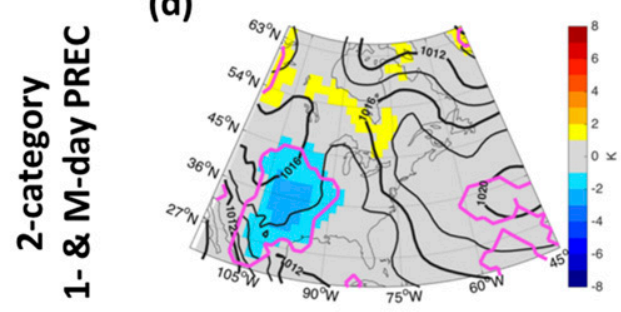

(g)
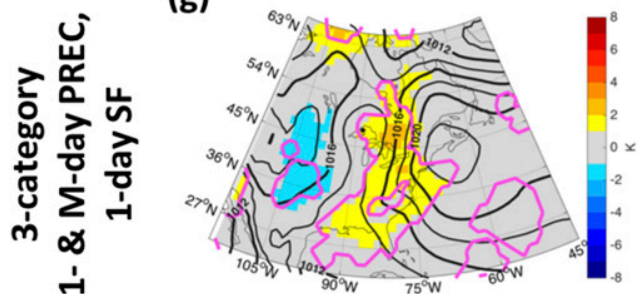

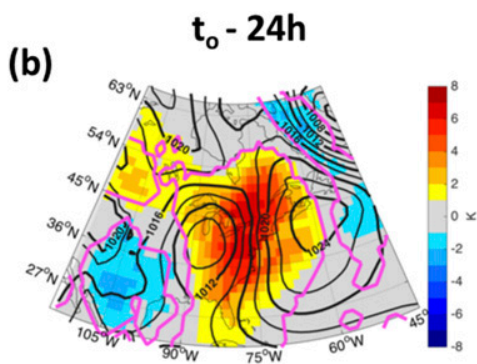

(e)

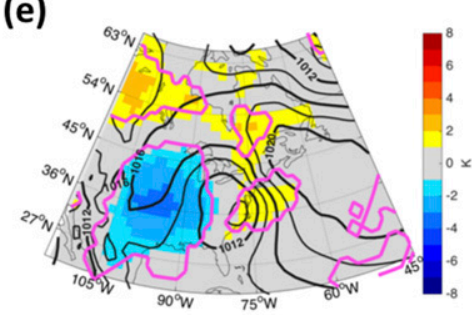

(h)

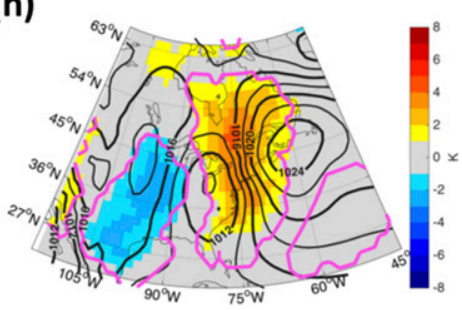

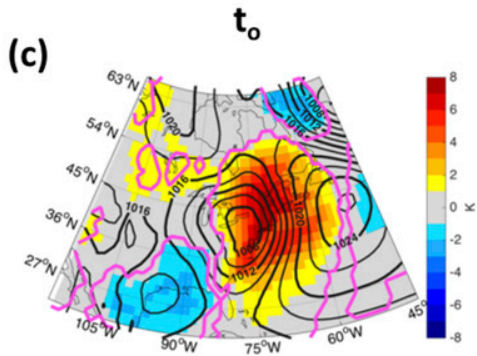

(f)

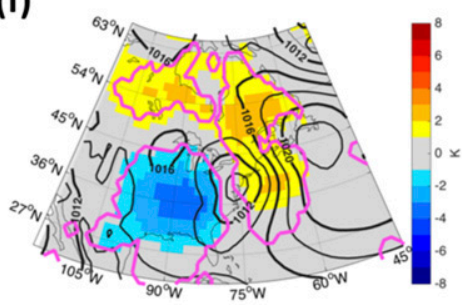

(i)

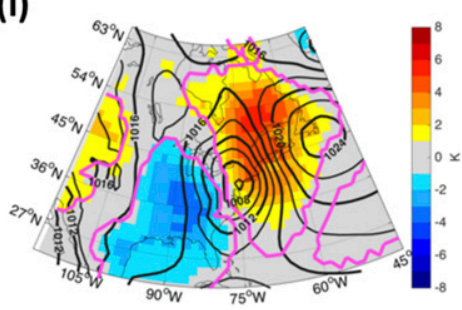

FIG. 8. Composites for (top) isolated streamflow events, (middle) concurrent 1-day precipitation and multiday precipitation events, and (bottom) three-category events for (a),(d),(g) $48 \mathrm{~h}$ prior to the event; (b),(e),(h) $24 \mathrm{~h}$ prior to the event; and (c),(f),(i) the day of the event for 2-m temperature anomalies (K; shading) and averaged mean sea level pressure (hPa; black contours). Anomaly fields of statistical significance at the 99 th percentile are contoured in magenta.

highest ranked events, indicative of some of the heaviest precipitation events resulting in the biggest floods. Thus, each category of events imposes their own threats on the watershed.

\section{Summary}

This study categorizes the contribution of ETCs and TCs in relation to the top 100 basin-scale 1-day precipitation, multiday precipitation, and 1-day streamflow events. In the Ashokan reservoir, ETCs are the primary storm type associated with all hydrometeorological metrics. TCs account for $20 \%$ of the top 100 one-day precipitation events and less than $10 \%$ of the top 100 one-day streamflow events. However, the probability of a TC that passes within $500 \mathrm{~km}$ of Ashokan causing a top 100 one-day precipitation or one-day streamflow event is significantly larger than that of an ETC. Furthermore, $70 \%$ of all TCs that caused 1-day precipitation events underwent extratropical transition. The composite analysis for the top 100 one-day precipitation events shows a clear distinction between antecedent synoptic-scale circulation features associated with TCs and ETCs. Compared to TCs, ETCs have relatively less moisture available, but exhibit strong upper-level support for vertical motion associated with a negatively tilted trough. TCs have relatively more moisture available than ETCs do, but less upper-level support for vertical motion.

Based on the cyclone tracks, ETCs associated with top 100 one-day precipitation events in DJF and SON are more likely to take a meridional path. This path suggests that a cold front associated with an ETC propagating northward could be the cause of the event. In MAM and JJA, ETCs that result in top 100 one-day precipitation events are more likely to propagate zonally, suggesting that the precipitation may be primarily generated by the warm front of an ETC.

The top 100 one-day precipitation and multiday precipitation events occur more often during the warm season whereas the top 100 one-day streamflow events occur mainly in the cool season. However, approximately $43 \%$ of the 1-day precipitation, multiday precipitation, and 1-day streamflow events are associated with the same storm, or in a few cases, multiple storms. These three-category events are found to occur 
throughout the year and, on average, result in more intense precipitation and streamflow events than both one- and two-category events. Composites of isolated streamflow events indicate that antecedent warming and moistening of the environment is essential to these events, suggesting snowmelt could be associated with the one-category streamflow events.

These results show that there are distinct synopticscale signals related to the seasonality and storm type of the strongest precipitation and streamflow events that can be incorporated into any planning or forecasting analysis for the Ashokan reservoir as well as the surrounding area, though the framework presented here can be easily replicated for any location. A common priority to all watershed managers is the issue of flood control (Frei and Kelly-Voicu 2017). It is clear from this analysis that ETCs require as much attention and planning as TCs for heavy precipitation events. A medium-range forecast from a weather model is likely to have smaller biases in the representation of synopticscale features and the mean sea level pressure distribution compared to the location and magnitude of precipitation. Therefore, when evaluating the confidence of a hydrometeorological event occurring 5-7 days in advance, forecasters can utilize anomalies of synopticscale features as preliminary indications concerning the magnitude of a hydrometeorological event. The evolution of the large-scale atmospheric circulation detailed here provides a benchmark for future analyses. Such documentation is especially important given that the frequency of heavy precipitation and high streamflow events and their causes may change with climate change. The analysis also provides forecasters and water managers additional guidance when identifying unique patterns and anomalies in longer-range forecasts that aim at controlling the extent of floods in watersheds.

Acknowledgments. All data used in this analysis are freely available (see section 2 for details). We thank the editor, Andrew Wood, and four anonymous reviewers for useful feedback that helped improve the analysis and presentation. K.L.T. and J.F.B. were partially funded by the NASA PMM Grant NNX16AD82G. A.F. was partially funded by the New York City Department of Environmental Protection Climate Change Integrated Modeling Project.

\section{REFERENCES}

Agel, L., M. Barlow, J.-H. Qian, F. Colby, E. Douglas, and T. Eichler, 2015: Climatology of daily precipitation and extreme precipitation events in the northeast United States. J. Hydrometeor., 16, 2537-2557, https://doi.org/10.1175/ JHM-D-14-0147.1.
, S. B. Feldstein, and W. J. Gutowski Jr., 2018: Identification of large-scale meteorological patterns associated with extreme precipitation in the US northeast. Climate Dyn., 50, 1819-1839, https://doi.org/10.1007/s00382-017-3724-8.

Barlow, M., 2011: Influence of hurricane-related activity on North American extreme precipitation. Geophys. Res. Lett., 38, L04705, https://doi.org/10.1029/2010GL046258.

Bauer, M., G. Tselioudis, and W. B. Rossow, 2016: A new climatology for investigating storm influences in and on the extratropics. J. Appl. Meteor. Climatol., 55, 1287-1303, https:// doi.org/10.1175/JAMC-D-15-0245.1.

Booth, J. F., H. E. Reider, D. E. Lee, and Y. Kushnir, 2015: The paths of extratropical cyclones associated with wintertime high-wind events in the northeastern United States. J. Appl. Meteor. Climatol., 54, 1871-1885, https://doi.org/10.1175/ JAMC-D-14-0320.1.

_ - _ and Y. Kushnir, 2016: Comparing hurricane and extratropical storm surge for the Mid-Atlantic and Northeast coast of the United States for 1979-2013. Environ. Res. Lett., 11, 094004, https://doi.org/10.1088/1748-9326/11/9/ 094004.

Catto, J. L., and S. Pfahl, 2013: The importance of fronts for extreme precipitation. J. Geophys. Res. Atmos., 118, 1079110 801, https://doi.org/10.1002/jgrd.50852.

Coles, S., 2001: An Introduction to Statistical Modeling of Extreme Values. Springer, 209 pp.

Dacre, H. F., P. A. Clark, O. Martinez-Alvarado, M. A. Stringer, and D. A. Lavers, 2015: How do atmospheric rivers form? Bull. Amer. Meteor. Soc., 96, 1243-1255, https://doi.org/ 10.1175/BAMS-D-14-00031.1.

Dee, D. P., and Coauthors, 2011: The ERA-Interim reanalysis: Configuration and performance of the data assimilation system. Quart. J. Roy. Meteor. Soc., 137, 553-597, https://doi.org/ 10.1002/qj.828.

Dumanski, S., J. W. Pomeroy, and C. J. Westbrook, 2015: Hydrological regime changes in a Canadian Prairie basin. Hydrol. Processes, 29, 3893-3904, https://doi.org/10.1002/hyp.10567.

Evans, C., and Coauthors, 2017: The extratropical transition of tropical cyclones. Part 1: Cyclone evolution and direct impacts. Mon. Wea. Rev., 145, 4317-4344, https://doi.org/10.1175/ MWR-D-17-0027.1.

Evans, J. L., and R. E. Hart, 2003: Objective indicators of the life cycle evolution of extratropical transition for Atlantic tropical cyclones. Mon. Wea. Rev., 131, 909-925, https://doi.org/ 10.1175/1520-0493(2003)131<0909:OIOTLC $>2.0 . C O ; 2$.

Folland, C. K., 1988: Numerical models of the raingauge exposure problem, field experiments, and an improved collector design. Quart. J. Roy. Meteor. Soc., 114, 1485-1516, https://doi.org/ 10.1002/qj.49711448407.

Frei, A., and P. Kelly-Voicu, 2017: Hurricane Irene and Tropical Storm Lee: How unusual were they in the Catskill Mountains? J. Extreme Events, 4, 1750009, https://doi.org/10.1142/ S2345737617500099.

, K. E. Kunkel, and A. Matonse, 2015: The seasonal nature of extreme hydrological events in the northeastern United States. J. Hydrometeor., 16, 2065-2085, https://doi.org/10.1175/ JHM-D-14-0237.1.

Galarneau, T. J., Jr., L. F. Bosart, and R. S. Schumacher, 2010: Predecessor rain events ahead of tropical cyclones. Mon. Wea. Rev., 138, 3272-3297, https://doi.org/10.1175/2010MWR3243.1.

Gilleland, E., and R. W. Katz, 2016: extRemes 2.0: An extreme value analysis package in R. J. Stat. Software, 72, 1-39, https:// doi.org/10.18637/jss.v072.i08. 
Groisman, P. Ya., and D. R. Legates, 1994: The accuracy of United States precipitation data. Bull. Amer. Meteor. Soc., 75, 215-227, https://doi.org/10.1175/1520-0477(1994)075<0215: TAOUSP $>2.0 . \mathrm{CO} ; 2$

Hart, R. E., 2003: A cyclone phase space derived from thermal wind and thermal asymmetry. Mon. Wea. Rev., 131, 585-616, https://doi.org/10.1175/1520-0493(2003)131<0585:ACPSDF $>2.0$. $\mathrm{CO} ; 2$.

Hawcroft, M. K., L. C. Shaffrey, K. I. Hodges, and H. F. Dacre, 2012: How much Northern Hemisphere precipitation is associated with extratropical cyclones? Geophys. Res. Lett., 39, L24809, https://doi.org/10.1029/2012GL053866.

Hersbach, H., C. Peubey, A. Simmons, P. Berrisford, P. Poli, and D. Dee, 2015: ERA-20CM: A twentieth-century atmospheric model ensemble. Quart. J. Roy. Meteor. Soc., 141, 2350-2375, https://doi.org/10.1002/qj.2528.

Ivancic, T. J., and S. B. Shaw, 2015: Examining why trends in very high precipitation should not be mistaken for trends in very high river discharge. Climatic Change, 133, 681-693, https:// doi.org/10.1007/s10584-015-1476-1.

Konrad, C. E., II, 2001: The most extreme precipitation events over the eastern United States from 1950 to 1996: Considerations of scale. J. Hydrometeor., 2, 309-325, https://doi.org/10.1175/ 1525-7541(2001)002<0309:TMEPEO > 2.0.CO;2.

Kunkel, K. E., D. R. Easterling, D. A. R. Kristovich, B. Gleason, L. Stoecker, and R. Smith, 2012: Meteorological causes of the secular variations in observed extreme precipitation events for the conterminous United States. J. Hydrometeor., 13, 11311141, https://doi.org/10.1175/JHM-D-11-0108.1.

Landsea, C. W., and J. L. Franklin, 2013: Atlantic hurricane database uncertainty and presentation of a new database format. Mon. Wea. Rev., 141, 3576-3592, https://doi.org/10.1175/ MWR-D-12-00254.1.

Marquardt Collow, A. B., M. G. Bosilovich, and R. D. Koster, 2016: Large-scale influences on summertime extreme precipitation in the northeastern United States. J. Hydrometeor., 17, 3045-3061, https://doi.org/10.1175/JHM-D-16-0091.1.

Matonse, A. H., and A. Frei, 2013: A seasonal shift in the frequency of extreme hydrological events in southern New York state. J. Climate, 26, 9577-9593, https://doi.org/10.1175/JCLI-D-1200810.1.

, D. C. Pierson, A. Frei, M. S. Zion, A. Anandhi, E. Schneiderman, and B. Wright, 2013: Investigating the impact of climate change on New York City's primary water supply. Climatic Change, 116, 437-456, https://doi.org/10.1007/ s10584-012-0515-4.

Milrad, S. M., E. H. Atallah, and J. R. Gyakum, 2009: Synopticscale characteristics and precursors of cool-season precipitation events at St. John's, Newfoundland, 1979-2005. Wea. Forecasting, 24, 667-689, https://doi.org/10.1175/ 2008WAF2222167.1.

,,--- , and G. Dookhie, 2014: Synoptic typing and precursors of heavy warm-season precipitation events at Montreal, Quebec. Wea. Forecasting, 29, 419-444, https:// doi.org/10.1175/WAF-D-13-00030.1.

Moore, B. J., K. M. Mahoney, and E. M. Sukovich, 2015: Climatology and environmental characteristics of extreme precipitation events in the southeastern United States. Mon. Wea. Rev., 143, 718-741, https://doi.org/10.1175/ MWR-D-14-00065.1.

Nakamura, J., U. Lall, Y. Kushnir, A. W. Robertson, and R. Seager, 2013: Dynamical structure of extreme floods in the U.S. Midwest and the United Kingdom. J. Hydrometeor., 14, 485-504, https://doi.org/10.1175/JHM-D-12-059.1.

Newton, B., and B. C. Burrell, 2016: The April-May 2008 flood event in the Saint John River Basin: Causes, assessment and damages. Can. Water Resour. J., 41, 118-128, https://doi.org/ 10.1080/07011784.2015.1009950.

NYCDEP, 2018: Ashokan. Accessed 21 May 2018, http://www nyc.gov/html/dep/html/watershed_protection/ashokan. shtml.

Pfahl, S., and H. Wernli, 2012: Quantifying the relevance of cyclones for precipitation extremes. J. Climate, 25, 6770-6780, https://doi.org/10.1175/JCLI-D-11-00705.1.

Pradhanang, S. M., A. Anandhi, R. Mukundan, M. S. Zion, D. C. Pierson, E. M. Schneiderman, A. Matonse, and A. Frei, 2011: Application of SWAT model to assess snowpack development and streamflow in the Cannonsville watershed, New York, USA. Hydrol. Processes, 25, 3268-3277, https://doi.org/10.1002/ hyp. 8171 .

- A. Frei, M. Zion, E. M. Schneiderman, T. S. Steenhuis, and D. Pierson, 2013: Rain-on-snow runoff events in New York. Hydrol. Processes, 27, 3035-3049, https://doi.org/10.1002/ hyp. 9864 .

Rasmussen, R., and Coauthors, 2012: How well are we measuring snow: The NOAA/FAA/NCAR winter precipitation test bed. Bull. Amer. Meteor. Soc., 93, 811-829, https://doi.org/10.1175/ BAMS-D-11-00052.1.

R Core Team, 2014: R: A language and environment for statistical computing. R Foundation for Statistical Computing, http:// www.R-project.org/.

Schumacher, R. S., and R. H. Johnson, 2006: Characteristics of U.S. extreme rain events during 1999-2003. Wea. Forecasting, 21, 69-85, https://doi.org/10.1175/WAF900.1.

Seager, R., N. Pederson, Y. Kushnir, J. Nakamura, and S. Jurburg, 2012: The 1960s drought and the subsequent shift to a wetter climate in the Catskill Mountains region of the New York City watershed. J. Climate, 25, 6721-6742, https://doi.org/10.1175/ JCLI-D-11-00518.1.

Sevruk, B., 1982: Methods of correction for systematic error in point precipitation measurement for operational use. WMO Operational Hydrology Rep. 21, 91 pp.

Sinclair, M. R., 2002: Extratropical transition of southwest Pacific tropical cyclones. Part I: Climatology and mean structure changes. Mon. Wea. Rev., 130, 590-609, https://doi.org/ 10.1175/1520-0493(2002)130<0590:ETOSPT > 2.0.CO;2.

Teale, N. G., S. M. Quiring, and T. W. Ford, 2017: Association of synoptic-scale atmospheric patterns with flash flooding in watersheds of the New York City water supply system. Int. J. Climatol., 37, 358-370, https://doi.org/10.1002/joc.4709.

Utsumi, N., H. Kim, S. Kanae, and T. Oki, 2017: Relative contributions of weather systems to mean and extreme global precipitation. J. Geophys. Res. Atmos., 122, 152-167, https:// doi.org/10.1002/2016JD025222. 